Reseñas

\title{
Harvey, David, 2003 [2000], Espacios de esperanza, Madrid, Akal.
}

E spacios de esperanza surge de la iniciativa por analizar la dimensión política del espacio a partir de las condiciones sociales que caracterizan las últimas décadas del siglo XX, para lo cual David Harvey elabora una lectura crítica de la teoría marxista en la que reconoce su vigencia y necesaria actualización. Son cuatro apartados generales los que constituyen esta obra, producto de una serie de ensayos editados anteriormente de forma aislada, los cuales tienen como ejes temáticos: 1) el estudio de la globalización con base en las dinámicas capitalistas desiguales, 2) la dimensión activa del sujeto corporal, 3) la utopía como proyecto realizable de forma material y 4) las alternativas tanto políticas como epistemológicas que intervienen en la construcción de una teoría del espacio social, tomando en cuenta los debates contemporáneos respecto a las formas de comprender y llevar a cabo las relaciones de poder. La obra parte de una perspectiva dialéctica que problematiza el posicionamiento de los agentes particulares y los escenarios de alcance mundial que intervienen en las estrategias y modos de conceptualizar la organización espacial así como el desarrollo geográfico planetario.

\section{Primera parte: desarrollos geográficos desiguales}

La propuesta de Harvey tiene como base el denominado "materialismo histórico-geográfico", considerado un método de análisis social que pone especial énfasis en los modos de acumulación desigual del capital, y su expresión en distintas formas de organización espacial; por ejemplo, en las composiciones arquitectónicas de las fábricas, las casas y los edificios, en las construcciones urbanas, o en las delimitaciones territoriales de carácter regional y nacional. En este sentido, los distintos niveles de espacialidad conforman un campo de análisis del capitalismo que incluye las relaciones de carácter geopolítico, sus repercusiones en la producción de formas de acumulación y la construcción de alternativas frente a las formas hegemónicas de poder.

Harvey ubica la dimensión geográfica de la teoría marxista a partir de una revisión del Manifiesto comunista, cuya lectura le permite introducir la relevancia de un enfoque dirigido a las diversas condiciones locales en las que surge el capitalismo y los variados efectos planetarios, considerando las formas tan distintas que éste adquiere en la globalización contemporánea. Al respecto considera: "la fuerza de trabajo está ahora geográficamente mucha más dispersa, es culturalmente mucho más heterogénea, étnica y religiosamente más diversa, está racialmente más estratificada y lingüísticamente fragmentada" (Harvey, 2003 [2000]: 62). Precisamente, el desarrollo geográfico desigual aparece como una posibilidad de llevar el análisis convencional sobre la lucha de clases y los movimientos proletarios hacia 
formas más complejas de teorizar el capitalismo en el cual intervienen las condiciones ecológicas, políticas, económicas y culturales que no responden a valores y aspiraciones homogéneas sino a condiciones y diversidades geográficas e históricas.

La propuesta de Harvey consiste en realizar una revisión de los conceptos y del aparato político del pensamiento marxista para dar cabida al análisis de los movimientos sociales que se incrementaron en las últimas décadas del siglo XX, en torno a los derechos humanos, las condiciones ambientales, la situación de las mujeres y los grupos minoritarios. Esto implica una disposición teórica para observar con mayor flexibilidad las formaciones políticas que se ponen en juego dentro de las dinámicas capitalistas desiguales, recuperando, en este sentido, las alteridades y diferencias culturales, económicas y sociales que surgen en los espacios locales pero con proyección a nivel planetario.

Integrar las distintas espacialidades, las múltiples formas de acumulación del capital, la diversidad de luchas y estrategias políticas, tanto en la teoría como en la práctica marxista, es precisamente el objetivo que propone Harvey. Para ello, discute el papel que adquieren las innovaciones tecnológicas, los medios de comunicación y transporte en la construcción de infraestructuras físicas, en los costos y tiempos necesario para la movilidad de mercancías y personas, en los roles económicos que adquiere el Estado; todo lo cual está implicado en las formas de producción capitalista, su apropiación y control de espacios específicos así como su impacto en la constitución de un proletariado mundial, geográficamente disperso y culturalmente heterogéneo, agudizado por la migración, las concentraciones masivas en las ciudades y regiones urbanas.

Para Harvey, los desarrollos geográficos desiguales requieren, en última instancia, la posibilidad de plantear universales políticos y reivindicaciones planetarias que tomen en cuenta la producción de escalas espaciales y diferencias geográficas donde los múltiples intereses particulares conformen un marco de acción y conocimiento que sea de interés general. En contra de un relativismo desenfrenado o un ilimitado eclecticismo posmoderno, se plantea la discusión respecto a las relaciones dialécticas entre comunidad/diferencia, la particularidad de la una y el universalismo de la otra. El caso de los derechos humanos es uno de los campos que aparece plagado de dificultades respecto a las formas de asumir su aplicabilidad mundial, respetando el derecho de cada cual a la diferencia, sin que se conviertan en un vehículo para la sujeción o la dominación de intereses excluyentes.

Harvey argumenta que es necesario refutar las interpretaciones inflexibles e intolerantes respecto a los derechos humanos, tanto aquellas ideas que surgen desde un lectura estrictamente marxista, las cuales identifican el derecho como producto de instituciones burguesas que deben ser erradicadas, así como los discursos posmodernos que los consideran erróneos patrones del pensamiento irreconciliables con la defensa de la alteridad. No obstante, aún cuando la aplicación y formulación de los derechos humanos es problemática, su defensa y realización supone para el autor transformaciones masivas. En el caso de las reivindicaciones económicas considera que "el neoliberalismo se podría tachar, por ejemplo, de flagrante conculcación de los derechos humanos" (112). En este sentido, un análisis sobre el desarrollo geográfico desigual, desde el capitalismo y la política de la globalización, abre terrenos de discusión respecto a las formas de reivindicación sociales, hace presente la pregunta por la "condición humana", su "ser genérico" visto desde una escala universal hasta la microescala del cuerpo y la persona política.

\section{Segunda parte: sobre los cuerpos y las personas políticas en el espacio global}

El cuerpo como "la medida de todas las cosas" es un campo de conocimiento con una tradición filosófica amplia que cobra mayor interés en los debates contemporáneos de género, sexualidad y poder. Harvey 
plantea una forma dialéctica de acceder a este tema, a partir de la "teoría del sujeto corporal de Marx", la cual pone en conexión los procesos histórica y geográficamente diversificados con la dimensión activa del individuo, su relación porosa con el entrono, el otro y la naturaleza. Marx señala desde El Capital el papel que juega el cuerpo, modelado por las fuerzas externas de la circulación y la acumulación, como punto de origen de los procesos transformadores, del deseo de reforma y rebelión. Harvey lo plantea aquí a manera de pregunta, "los obreros están necesariamente alienados porque los capitalistas se apropian de sus capacidades creativas a través de la mercancía fuerza de trabajo. Pero podemos ampliar la cuestión: iqué efecto tiene la circulación de capital variable en los cuerpos de aquellos a través de quienes circula?" (125). Precisamente, esta interrogante conduce al análisis social de los impulsos, los afectos, las fuerzas reactivas que intervienen en la "circulación del capital variable" durante la producción, el intercambio y el consumo individual.

En principio, Harvey considera que la producción capitalista exige ciertas habilidades creativas pues aun cuando en ella persiste un riguroso aparato disciplinario de control y castigo, el desarrollo del capitalismo se debe, en gran medida, al descubrimiento de nuevas formas de usar el cuerpo humano como portador de la capacidad de trabajar y producir plusvalor. De igual modo, desde la teoría marxista, el intercambio del obrero con el capitalista no se reduce a la fuerza de trabajo que aquel ejerce y el pleno derecho que éste adquiere sobre la mercancía que produce el trabajador, pues el cuerpo sigue siendo el campo primero de posibilidades donde tiene lugar la protesta y lucha laboral.

Finalmente, el trabajador como consumidor en posesión del dinero crea estrategias para elegir estilos de vida, preferencias de demanda que influyen en la decisión capitalista sobre las cosas que se producen. En este sentido, "el capital variable no determina la naturaleza específica de las decisiones de los consumidores, ni siquiera de la cultura de los consumidores, aunque ciertamente tiene un efecto poderoso" (136). Aun cuando el capitalismo tiende a moldear los cuerpos de acuerdo con sus propias exigencias, se interiorizan en él los cambios y deseos, las carencias y necesidades sociales manifestadas por los trabajadores.

Harvey afirma que el estudio de la "circulación del capital variable" está marcado por el desarrollo geográfico desigual, los contextos históricos y culturales, por las distinciones de raza, etnia, edad y género que el propio capitalismo produce para distinguir las capacidades y calidades productivas de los diversos tipos de trabajador. La teoría de Marx sobre los procesos de producción corporal y sus representaciones en el capitalismo permite acceder a un campo de análisis que pone a discusión los fenómenos sociales contemporáneos, a partir de los agenciamientos de poder que componen la individualidad activa. Al respecto, Harvey considera que es necesario acceder con nuevas perspectivas a cuestiones como la sexualidad, el erotismo, la psicología, la lingüística, los imaginarios y los mitos, con la intención de ampliar el enfoque marxista de las reflexiones sobre el cuerpo político y la política del cuerpo.

La política del cuerpo, concentrada en los procesos de producción, intercambio y consumo capitalista, adquiere un carácter activo y problemático en la medida que también se reconoce al cuerpo individual como el campo donde se ponen en juego los poderes y contrapoderes de la vida social. El trabajador no sólo es portador de la mercancía fuerza de trabajo, además, "esa persona es portadora de ideales y aspiraciones referentes, por ejemplo, a la dignidad de trabajo y al deseo de recibir un trato respetuoso y considerado como ser vivo integral y de tratar a los otros de igual manera" (142). Harvey presenta una crónica basada en su experiencia en la ciudad de Baltimore, desde la década de 1960, en la que muestra cómo se producen los cambios en la "circulación del capital variable"; los efectos sobre las condiciones y prácticas corporales que se concretizan en la reivindicación de un salario digno, a partir de la defensa de un sistema universal de los derechos huma- 
nos, con la intervención de organizaciones religiosas, sindicatos, grupos universitarios, estratos del gobierno y sociedad civil.

El caso de Baltimore pone al descubierto la necesidad de ampliar el pensamiento marxista hacia los distintos fenómenos sociales que confluyen en las dinámicas capitalistas contemporáneas. Así también, permite valorar cómo las transformaciones en las prácticas corporales, que se producen a partir de la lucha por un salario digno, no conducen necesariamente a una reforma total respecto a la calidad de las condiciones de vida de los trabajadores, pero posibilitan la aparición de otras tantas exigencias, además de la formación de nuevos actores y estrategias sociales. El estudio en Baltmirore refleja, finalmente, las problemáticas, temas y discusiones que confluyen en un análisis enfocado a una escala espacial con diferencias geográficas e históricas específicas dentro del capitalismo global.

\section{Tercer parte: el momento utópico}

La historia de Baltimore es un referente clave para concretar la propuesta teórica respecto al desarrollo geográfico desigual; Harvey toma como punto de partida las contradicciones en la escala urbana, señalando, por ejemplo, las particularidades que presenta Baltimore a causa del número creciente de personas sin hogar en correspondencia con las casas abandonadas por las familias que prefieren desplazarse a las zonas residenciales que rodean la ciudad; muestra las desigualdades en oportunidades y niveles de vida, las disparidades en cuanto riquezas y poder, cuestiona los proyectos públicos y privados que pretenden revitalizar a las comunidades empobrecidas fomentando el traslado de los marginados hacia los suburbios. El tema de Baltimore se ubica precisamente en la confrontación de los distintos modos de aprovechamiento del espacio con los que se conforma la ciudad, las formas como interviene el capitalismo en su dinámica y organización. Esta perspectiva también propone opciones para construir discursos y prácticas de la vida urbana, tomando en cuenta los significados de la "ciudad", las emociones y las pasiones políticas, expresadas en expectativas utópicas.

En las observaciones sobre Baltimore, la ciudad es analizada como el lugar del extraño anónimo, de los marginados, el ámbito de una inabarcable alteridad, el terreno de contaminación moraly física, de las múltiples corrupciones que pretenden ser encerradas y controladas en los límites de los suburbios. La función de la imaginación humana como una tarea social para "rehacernos a nosotros mismos" desempeña un papel importante frente a este panorama, pues permite explorar fuera de los mundos institucionales, delos entornos construidos y definir modelos utópicos que visualicen la ciudad a partir de nuevos proyectos que puedan ser realizados de forma material. Por esto, se propone una diferenciación entre las "utopías de forma espacial" y las "utopías como proceso social" para después plantear un utopismo dialéctico espacio-temporal, recuperandolas características y las problemáticas que se ponen en juego en ambas perspectivas.

Harvey parte de los proyectos utópicos que surgen con Tomas Moro, Bacon y Campanella, más adelante menciona aquellos de corte feminista del siglo XIX y afirma que "estas formas de utopías se pueden caracterizar como 'utopías de forma espacial', ya que la temporalidad del proceso social, la dialéctica del cambio social - la historia real - se excluyen, mientras que la estabilidad social se garantiza mediante una forma espacial fija" (188). En general, considera que las utopías de este tipo abren una infinita gama de ordenamientos espaciales que ofrecen una igual cantidad de mundos posibles; esto testifica la capacidad de la imaginación humana para explorar soluciones socioespaciales, sin embargo, dichas utopías corren el peligro de materializarse con una fuente inextricable de autoridad, con formas restrictivas de gobierno, vigilancia y control. Precisamente, las "utopías degeneradas" ponen especial énfasis en un espacio armonioso, sin conflicto, apartado del mundo "real exterior", todo esto para suavizar e inventar la historia, o cultivar la nostalgia por un pasado mítico. 
Para Harvey, las utopías espaciales logran materializarse únicamente en casos como Disneylandia, en los centros comerciales, las zonas residenciales y a partir del "nuevo urbanismo" que sólo de manera superficial asume una responsabilidad social, pues en la práctica se convierte en una retórica de orgullo y conciencia cívica, exclusión de clases y marginación.

Por otra parte, la "utopía como proceso social" se expresa habitualmente en términos temporales, no está ligada a ningún lugar y se desenvuelve generalmente fuera de las limitaciones espaciales. Para Harvey, la historia del capitalismo aparece como el caso más perfecto de este tipo de utopismo, recuperado desde la mirada de los economistas políticos del siglo XIX, en específico, de Adam Smith de quien dice lo siguiente:

sus reflexiones sobre la teoría de los sentimientos morales lo llevaron a proponer un utopismo de proceso en el que los deseos individuales, la avaricia, la codicia, los impulsos, la creatividad, etcétera, pudiesen movilizarse mediante la mano oculta del mercado perfecto para beneficio social de todos (203).

Precisamente, frente a los mercados libres de espacio como la ideología predominante del capitalismo, surgió la crítica marxista, la cual denuncia las inevitables consecuencias reaccionarias de ese utopismo degenerado que se encarna bajo la forma del desarrollo geográfico desigual.

Para Harvey, tanto las "utopías espaciales" como aquellas que aparecen ligadas a "procesos sociales" sólo han logrado realizarse de forma corrupta y degenerada, lo cual no significa la negación de la utopía misma sino su necesaria reformulación a partir de los contextos históricos particulares. Esto mismo lo señalaron Marx y Engels, quienes se opusieron al utopismo propuesto por Adam Smith, pero

sostuvieron en el Manifiesto Comunista que hay momentos históricos en los que las fuerzas de oposición están en un estado tan subdesarrollado que "las fantásticas descripciones de una sociedad futura" pasan a representar "las primeras aspiraciones" de una "completa transformación de la sociedad" (225).

En este sentido, el utopismo dialéctico plantea explorar los distintos proyectos que pueden surgir del interés común, de la imaginación plural y colectiva, negociando la formulación de espacios y prácticas que se materialicen en formas congruentes, socialmente dignas y responsables.

Harvey considera que las visiones utópicas, a pesar de lo fantásticas que puedan parecer, se convierten en una demanda imperante para nuestros días pues en ellas persiste la disposición de aspirar, desear y pensar desde horizontes políticos y epistemológicos diferentes. La creación literaria, en especial la novela, adquiere un papel importante desde esta perspectiva, dado que introduce posibles sociedades y especialidades a partir de imágenes flexibles del mundo, las cuales, en la media que se articulan con las condiciones histórico-geográficas particulares, permiten el desarrollo del "utopismo dialéctico" De este modo, el espacio deja de ser un recipiente estático, se convierte en un campo social que opera en relación con el tiempo, partícipe de las dinámicas y las trayectorias de la vida presente, capaz de reconstruirse con base en la confrontación de opciones e inevitable toma de decisiones.

\section{Cuarta parte: conversaciones sobre la pluralidad de alternativas}

Harvey plantea una serie de temáticas que posibilitan la creación de propuestas teóricas y epistemológicas para un conocimiento dialéctico, con base en los procesos materiales dentro de las dinámicas espacio-temporales. A partir de la figura del arquitecto - o de las abejas, en términos de Marx - quien por medio de su trabajo representa la materialización de los anhelosindividuales y colectivos, de la voluntad e imaginación creadora, se ponen al descubierto las polémicas respecto a las capa- 
cidades y potencialidades humanas para obrar y tomar decisiones. La cuestión se plantea en los siguientes términos: "icómo puede [...] la imaginación humana, tan aprovechada en El capital, moverse con suficiente libertad fuera de las condiciones materiales e institucionales existentes, llegando a conceptuar incluso cuál podría ser la alternativa socialista?" (233).

El problema radica en explicar cómo surge el potencial de la imaginación humana, asumir que se desarrolla bajo cualquier condición espacio-temporal, de modo que el propio capitalismo la necesita para su perpetuación, aun cuando también es frente a las condiciones materiales predominantes que pueden crecer imaginarios alternos por realizarse. Todo esto presupone para Harvey capacidades específicas del ser humano como "ser genérico", las cuales dependen de la facultad de crear y transgredir las jerarquías políticas, las condiciones medioambientales, las organizaciones sociales, la producción de espacios y ordenamientos temporales. Son, precisamente, los modos como se combinan y entran en contradicción estos elementos, los que actualizan la fuerza creadora que se resuelve por medio de la imaginación.

En este sentido, se considera que es una responsabilidad de los hombres y las mujeres hacia la "naturaleza" y la "naturaleza humana" tomar decisiones conscientes sobre aquello que cada cual desea; encontrar fundamentos, objetivos sociales y políticos comunes capaces de reconocer al ser humano como inserto en un flujo continuo de procesos vivos que dependen, en gran medida, de las acciones individuales y colectivas. Para Harvey, "somos agentes activos atrapados en "la red de la vida" (233), en un campo de negociaciones que componen el mundo, en donde intervienen todo tipo de consecuencias inesperadas, no necesariamente catastróficas o alarmistas, pero que afrontan los riesgo y la incertidumbre de los procesos que han derivado en masivas transformaciones industriales, tecnológicas, urbanas, demográficas, desarrollos desiguales acentuados desde la segunda mitad del siglo XX.
Las prácticas y decisiones que el ser humano adopta provienen de las potencialidades activas que asume la propia especie, en las formas de interpretar las relaciones con los otros, de traducir los contextos heterogéneos hacia leguajes y pensamientos comunes. La unidad de los diversos conocimientos desde la versión marxista es un tema recurrente que Harvey aborda a partir de los esfuerzos recientes de la "teoría de sistemas" o la "teoría de la complejidad", las cuales se enfocan a trabajar y relacionar diversas ramas disciplinarias y escalas científicas para propiciar una perspectiva epistemológica integral. Sin embargo, el autor considera que debe difundirse un mayor énfasis en las transformaciones cualitativas, históricas y geográficas, no en términos causativos, mecanicistas o meramente biologisistas.

Por su parte, Harvey considera que "la investigación dialéctica incorpora necesariamente [...] la elaboración de decisiones (valores) de tipo ético, moral y político en sus propios procesos, y contempla los conocimientos elaborados resultantes como discursos situados en un juego de poder" (263). Así, la unidad del conocimiento surge como un proceso vivo en constante competencia, diversificación, dispersión y difusión, en el que se exploran las potencialidades, estrategias y formas de práctica social. A partir de esto rescata, desde el planteamiento de corte marxista, la acción humana como una "fuerza de la naturaleza" que pone en marcha, desde diversas escalas espacio-temporales, a la voluntad creadora para asumir responsabilidades y proyectos colectivos, utopías cuyas implicaciones corren siempre el riesgo de no comprenderse ni controlarse por completo.

Sin embargo, Harvey destaca que toda acción política y propuesta teórica responsable implica tomar decisiones entre personas, eliminar posibilidades y confrontar las propias determinaciones, cierres y "cargas autoritarias". El reconocimiento del sujeto corporal como actor político posibilita el acercamiento al momento y al espacio irreductible donde se concentran las contradicciones teóricas, las problemáticas prácticas, los contextos vivos; es decir, las circunstancias y la con- 
ciencia que deriva de una actividad diaria localizada. El "arquitecto insurgente", como lo denomina Harvey, no surge mediante rupturas radicales sino de la disposición por desear y pensar desde la diferencia, buscando formas de negociar entre las seguridades conferidas por las instituciones fijas y la necesidad de ser abiertos, flexibles en relación con nuevas posibilidades socioespaciales. En este sentido se valora el pensamiento utópico dialéctico, pues además en él se traduce lo personal y político a un terreno más amplio para la acción humana, lejos de cualquier tipo de particularismo militante, fragmentación y relativización.

Los principios universales no refieren, en este caso, a una suerte de absolutización del conocimiento, sino al momento clave de tomar decisiones, al elegir los principios o códigos de acción, directrices que se modelan y ordenan para finalmente codificarse en lenguajes, leyes, instituciones y constituciones mediadoras. Harvey pretende enfrentar las protestas que surgen desde ciertos discursos de las ciencias sociales, los cuales no reconocen que la reivindicación de la diferencia requiere un momento para la universalidad, en la que se respalden los juicios y de donde surjan las demandas políticas. Nuevamente, el caso de los derechos humanos aparece como el campo de defensa del planteamiento de Harvey, pues aun cuando su aplicación e interpretación es discutible, en ellos pueden concentrarse las bases mínimas de convivencia, el momento formativo de un proceso social y teórico mucho más amplio que parta del reconocimiento del ser humano como "ser genérico" y de un pensamiento utópico dialéctico basado en las realidades y logros histórico-geográficos.

Finalmente, Harvey describe su propia Edilia en un tiempo que proclama la muerte de la utopía, desde la afrenta consabida: "no hay alternativas". En su esfuerzo por modelar una imagen del mundo que responda a los deseos y esperanzas sociales, a los principios de acción universales, a la responsabilidad política ante la acción y la construcción del pensamiento, rescata once principios básicos que considera ideales significativos, derechos universales propuestos, problematizados y justificados a partir de Espacios de esperanza: 1) El respeto a las oportunidades de vida, 2) a la asociación política y el "buen gobierno", 3) a la dignidad del trabajo, 4) a la integridad del cuerpo y la persona política, 5) a la libertad de pensamiento, conciencia y religión, 6) el derecho a un entorno vital decente y saludable, 7) al control colectivo de los recursos de propiedad común, 8) a las responsabilidades con las generaciones futuras de especies humanas y demás animales, 9) a la producción del espacio, formas territoriales y medios comunicativos, 10) a la diferencia, incluida la del desarrollo geográfico desigual, y ll) el derecho de explorar posibilidades de vida, en relación con la naturaleza e inherentes al ser genérico humano (284-288).

Yeri Paulina Mendoza Solís Alumna de maestría en CIESAS-SURESTE 